\title{
Synthesis of polyesteramides by a new palladium catalyzed carbonylation-polycondensation reaction
}

\author{
Shrikant M. Kulkarni, Ashutosh A. Kelkar and Raghunath V. Chaudhari* \\ Homogeneous Catalysis Division, National Chemical Laboratory, Pune - 411008 India. \\ E-mail: rvc@ems.ncl.res.in
}

Received (in Cambridge, UK) 18th April 2001, Accepted 30th May 2001 First published as an Advance Article on the web 21st June 2001

\begin{abstract}
Alternating polyesteramides are prepared by palladium catalyzed carbonylation-polycondensation reactions of aromatic diiodides and aminohydroxy compounds in the presence of an organic base.
\end{abstract}

Palladium catalyzed carbonylation-polycondensation reactions are emerging as a new versatile synthetic tool for the preparation of a number of high performance polymers such as polyamides, polyesters, polyimides, polybenzoxazoles, poly(acylhydrazides) etc. ${ }^{1-5}$ The most rewarding feature of these catalytic reactions is that they allow direct use of carbon monoxide, which is one of the cheapest and most easily available monomers. Conventionally, most of the above polymers are prepared by condensation reactions employing aromatic diacids or their suitable derivatives. One of the major problems associated with conventional condensation reactions is that they use corrosive and moisture sensitive acid chlorides as raw materials. Also, such condensation methods are suitable only if the appropriate diacid is easily available. However, difficulty arises if diacids with less common substitution patterns are required. Thus, it is highly desirable to have a simple alternative synthetic procedure for the synthesis of these polymers which do not require the presence of acid functionalities on the monomer. Palladium catalyzed carbonylationpolycondensation is certainly a promising reaction, at least on the laboratory scale for the preparation of such macromolecules.

We are currently exploring the synthetic utility of transition metal catalyzed carbonylation reactions in the preparation of functional polymers. Here, we report for the first time, on the synthesis of novel alternating polyesteramides by palladium catalyzed carbonylation-polycondensation reactions of aromatic diiodides with aminohydroxy compounds. Polyesteramides contain both ester and amide functions and thus are hybrid structures of polyesters and polyamides. These polymers are of interest because of their good heat resistance and gas barrier properties. ${ }^{6}$ Polyesteramides containing mesogenic biphenylene units would be of particular interest because of their liquid crystalline properties. Until now these polymers have been prepared by condensation of diacids or their derivatives with aminohydroxy compounds. The carbonylation route proposed here eliminates the need for diacid derivatives and provides a cleaner synthetic route.
The reaction of aromatic diiodides and aminohydroxy compounds in the presence of carbon monoxide, a catalytic amount of palladium complex and a base leads to carbonylation-polycondensation polymerization to give polyesteramides (Scheme 1). $\dagger$ The carbonylation reactions were carried out under comparatively mild conditions $\left(120^{\circ} \mathrm{C}\right.$ and $45 \mathrm{psi}$ of $\mathrm{CO}$ pressure) and a variety of polyesteramide derivatives were prepared using this approach. The results are presented in Table 1. Experiments using fully aromatic substrates (Table 1, entries 1 and 5) gave products which were insoluble in common solvents while those obtained from flexible units were soluble in $N$-methylpyrrolidone (NMP). A typical molecular weight of the THF soluble fraction of polyesteramide (Table 1, entry 2 ) as determined from GPC analysis was 5000 (polystyrene standard). All polymers exhibited distinct and characteristic IR frequencies corresponding to ester carbonyl (around 1720 $\mathrm{cm}^{-1}$ ) and amide carbonyl functional groups (around 3340 and $1640 \mathrm{~cm}^{-1}$ ). Thermogravimetric analysis (TGA) indicated that all polymers were stable in air up to at least $350{ }^{\circ} \mathrm{C}$. A typical proton NMR spectrum of the polyesteramide (Table 1, entry 2) shown in Fig. 1 is in accordance with the earlier literature report on similar polymers. ${ }^{7}$ The spectrum indicates the absence of any ether or amine linkages, at least in detectable amounts, (arising because of competing $N$ and/or $O$-arylation reactions) and confirms the structural homogeneity of the polyesteramide produced by the catalytic carbonylation route.

It was observed that no polyesteramide could be formed in the absence of a base. The organic base employed served as a scavanger for the HI released during the reaction course. Sterically hindered tertiary amines like 1,8-diazabicyclo[5.4.0] undec-7-ene (DBU) were particularly effective.

The effect of solvent on the carbonylation-polycondensation was investigated and results are presented in Table 2 . It was observed that the highest yield $(85 \%)$ of polyesteramide was obtained in chlorobenzene as solvent while no polymer was obtained in dichloromethane. Similarly, highest inherent viscosity $\left(0.25 \mathrm{dL} \mathrm{g} \mathrm{g}^{-1}\right)$ of the polyesteramide was obtained in chlorobenzene solvent.

$$
\mathrm{I}-\mathrm{Ar}-\mathrm{I}+\mathrm{H}_{2} \mathrm{~N}-\mathrm{R}-\mathrm{OH}+2 \mathrm{CO} \stackrel{\text { Pd catalyst }}{\text { Base }}+\mathrm{CO}-\mathrm{Ar}-\mathrm{CO}-\mathrm{NH}-\mathrm{R}-\mathrm{O}+\mathrm{H}_{n}
$$

Scheme 1 Polyesteramide synthesis by carbonylation-polycondensation.

Table 1 Synthesis and properties of polyesteramides ${ }^{a}$

\begin{tabular}{lllllll}
\hline Entry & Diiodide & Aminohydroxy compound & Yield $(\%)$ & {$[\eta]_{\mathrm{inh}}{ }^{c / \mathrm{dL} \mathrm{g}^{-1}}$} & $T_{10}{ }^{d /{ }^{\circ} \mathrm{C}}$ & $\mathrm{IR}\left(v / \mathrm{cm}^{-1}\right)$ \\
\hline 1 & 4,4'-Diiodobiphenyl & 4-Aminophenol & 95 & $-e$ & 410 & $3354,1727,1653,1531,1266,1194$ \\
2 & $4,4^{\prime}$-Diiodobiphenyl & 3-Aminopropan-1-ol & 85 & 0.25 & 320 & $3350,1712,1638,1542,1278,1111$ \\
3 & $4,4^{\prime}$-Diiodobiphenyl & 3-Aminobenzyl alcohol & 40 & 0.20 & 385 & $3371,1714,1648,1541,1274,1111$ \\
4 & 4,4'-Diiodobiphenyl & Ethanolamine & 35 & 0.18 & 331 & $3321,1718,1639,1541,1273,1108$ \\
5 & 1,4-Diiodobenzene & 4-Aminophenol & 90 & $-e$ & 430 & $3351,1729,1653,1509,1268,1196$ \\
6 & 1,4-Diiodobenzene & 3-Aminobenzyl alcohol & 25 & 0.17 & 392 & $3436,1716,1645,1542,1370,1107$
\end{tabular}

a Reaction conditions: diiodide: $5 \mathrm{mmol}$; aminohydroxy compound: $5 \mathrm{mmol}$; $\mathrm{PdCl}_{2}$ : $0.011 \mathrm{mmol}$; triphenylphosphine: $0.044 \mathrm{mmol}$; DBU: $10 \mathrm{mmol}$; chlorobenzene: $25 \mathrm{~mL}$, CO pressure: $45 \mathrm{psi}$; temperature: $120{ }^{\circ} \mathrm{C}$; agitation: $900 \mathrm{rpm}$; reaction time: 1 h. ${ }^{b}$ Isolated yields. ${ }^{c}[\eta]_{\text {inh }}($ intrinsic viscosity) measured at a concentration of $0.5 \mathrm{~g} \mathrm{dL}^{-1}$ in NMP at $30^{\circ} \mathrm{C} .{ }^{d} 10 \%$ weight-loss temperature $\left(T_{10}\right)$ in air determined by TGA. ${ }^{e}$ Insoluble in NMP. 


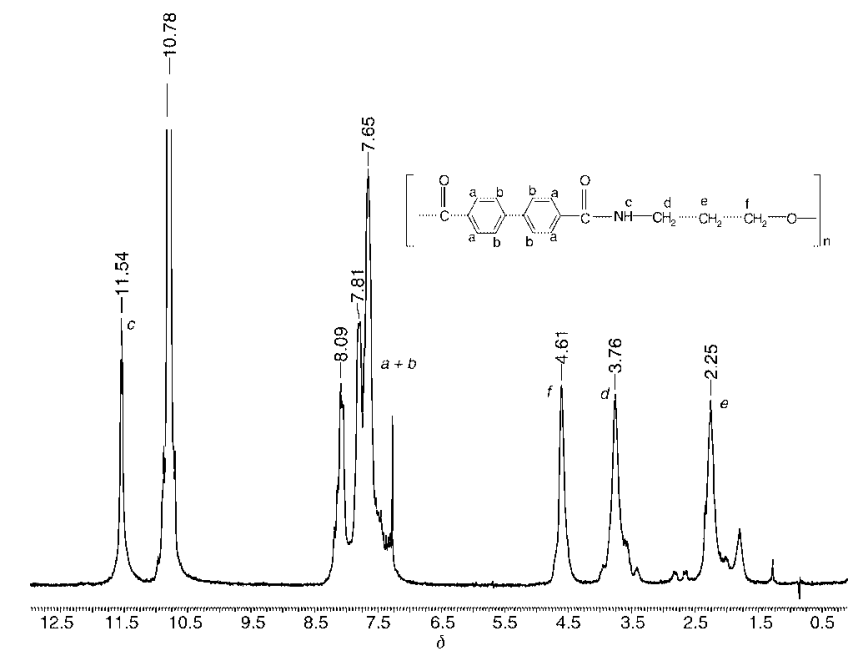

Fig. 1 Proton NMR spectra (200 MHz, trifluoroacetic acid-chloroform- $d_{1}$, 20:80) of the polyesteramide prepared by the carbonylation route (Table 1, entry 2).

The effect of temperature on polymer yield and viscosity was also investigated using chlorobenzene as a solvent and the results are given in Fig. 2. There was no significant change in the polymer yield as a function of temperature but the viscosity of the resulting polymer was influenced by the reaction temperature. The viscosity was highest at $120{ }^{\circ} \mathrm{C}$ and decreased above or below this temperature.

It is well known that $\mathrm{Pd}(0)$ complexes can oxidatively add aryl iodide even in the absence of added phosphine ligand

Table 2 The effect of solvent on polymerization ${ }^{a}$

\begin{tabular}{llll}
\hline Entry & Solvent & Yield $(\%)$ & {$[\eta]_{\text {inh }} / \mathrm{dL} \mathrm{g}^{-1}$} \\
\hline 7 & Chlorobenzene & 85 & 0.25 \\
8 & $N$-Methylpyrollidone & 20 & 0.11 \\
9 & $N, N$-Dimethylformamide & 60 & 0.17 \\
10 & $N, N$-Dimethylacetamide & 62 & 0.16 \\
11 & Toluene & 43 & 0.15 \\
12 & Dichloromethane & 0 & -
\end{tabular}

a Reaction conditions: 4,4'-diiodobiphenyl: 5 mmol; 3-aminopropan-1-ol: 5 $\mathrm{mmol}$; $\mathrm{PdCl}_{2}$ : $0.011 \mathrm{mmol}$; triphenylphosphine: $0.044 \mathrm{mmol}$; DBU: 10 mmol; solvent: $25 \mathrm{~mL}$, CO pressure: $45 \mathrm{psi}$; temperature: $120^{\circ} \mathrm{C}$; agitation: $900 \mathrm{rpm}$; reaction time: $1 \mathrm{~h}$.

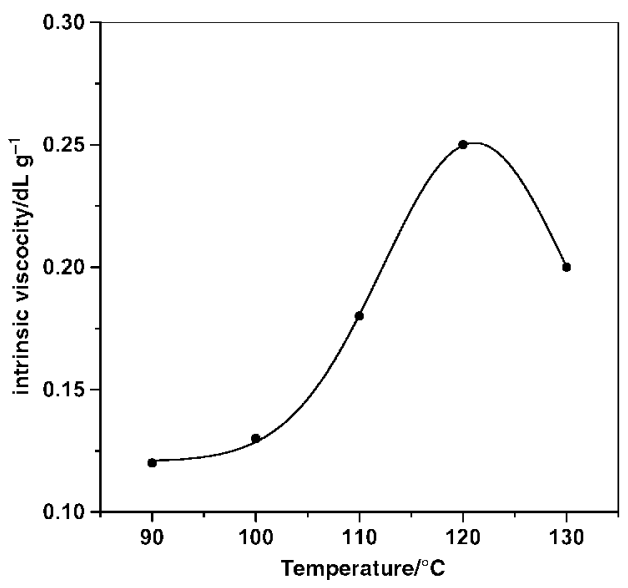

Fig. 2 Effect of temperature on intrinsic viscosity. because of the high reactivity of iodo derivatives. ${ }^{8}$ However, we preferred adding phosphine ligand during these studies for efficient separation and recycling of the catalyst. The polymers were insoluble in chlorobenzene and therefore could be separated by simple filtration or decantation. The filtrate containing the soluble $\mathrm{Pd}-$ phosphine complex was then recycled with fresh reactants. We found that even after four recycles, there was no appreciable loss in the catalytic activity, yield and the inherent viscosity of the resulting polymer.

It was also noted that the dibromoaromatics were less effecive in these reactions and the resulting polymers were obtained in lower yields and with lower viscosities than those obtained with the corresponding diiodoaromatics.

In conclusion, we have successfully demonstrated the application of palladium catalyzed carbonylation-polycondensation reaction for the preparation of polyesteramides. Our studies indicate that a variety of polyesteramides can be prepared efficiently by this method. This approach has three important advantages. First, it eliminates the need for corrosive, moisture-sensitive acid chlorides. Second, literature reports indicate the possibility of preparing a wide variety of diiodoaromatic substrates with high regioselectivity. ${ }^{9}$ Third, the catalyst and iodine recyclability is good. The iodide formed during the reaction can be reoxidized to iodine and used in the subsequent iodination to prepare the diiodoaromatics. ${ }^{1}$ The only serious problem at present seems to be the fairly low degree of polymerization. We are currently exploring this reaction in more detail to optimize reaction conditions to obtain higher molecular weight polyesteramides.

S. M. K. thanks the Council of Scientific and Industrial Research, New Delhi, India for the award of a Senior Research Fellowship for this work.

\section{Notes and references}

$\dagger$ Experimental procedure: polymerization reactions were carried out in a $50 \mathrm{~mL}$ capacity autoclave. The contents were charged into the reactor and flushed twice with nitrogen to ensure removal of air. The autoclave was then heated to the desired temperature. After the temperature had equilibrated at a set point, $\mathrm{CO}$ was introduced at the desired level. During the course of the reaction the $\mathrm{CO}$ pressure in the reactor was maintained constant by adding more $\mathrm{CO}$ as it was consumed. After completion of the reaction, the reactor was cooled and the excess $\mathrm{CO}$ vented. The polymers separated either as solids or viscous oils. The solution containing the catalyst was separated either by filtration or decantation accordingly. The crude polymer was dissolved in NMP and precipitated by methanol, filtered off and dried in vacuo

1 R. J. Perry, CHEMTECH, 1994, $2,18$.

2 Y. Kubota, K. Takeuchi, T. Hanoka and Y. Sugi, Bull. Chem. Soc. Jpn., 1994, 67, 563

3 R. J. Perry, S. E. Tunney and B. D. Wilson, Macromolecules, 1996, 29, 1014; R. J. Perry, B. D. Wilson, S. R. Turner and R. W. Belving, Macromolecules, 1995, 28, 3509; R. J. Perry and S. R. Turner, Makromol. Symp., 1991, 54/55, 159.

4 R. J. Perry and B. D. Wilson, Macromolecules, 1994, 27, 40.

5 M. Yoneyama, M. Kakimoto and Y. Imai, Macromolecules, 1989, 22, 4152.

6 R. B. Barbee and L. A. Minnick, US Pat., 4855397, 1989 (Chem. Abstr., 1989, 112, 78234).

7 P. J. M. Serrano, B. A. Van de Werff and R. J. Gaymans, Polymer, 1998, 39, 83.

8 A. Schoenberg, I. Bartoletti and R. F. Heck, J. Org. Chem., 1974, 39, 3318.

9 M. Rule, D. W. Lane, T. H. Larkins and G. C. Tustin, US Pat., 4746758 , 1988; M. Rule, D. W. Lane, T. H. Larkins and G. C. Tustin, US Pat., 4792641, 1988; M. Rule, D. W. Lane, T. H. Larkins and G. C. Tustin, US Pat., 4792642, 1988. 